\title{
METODE LEAST MEDIAN SQUARE (LMS) DALAM ANALISIS REGRESI ROBUST KETIKA TERDAPAT OUTLIER
}

\author{
Mimi Kurniati, Yundari, Setyo Wira Rizki
}

\begin{abstract}
INTISARI
Least median square (LMS) adalah salah satu metode estimasi dalam regresi robust yang digunakan untuk mengatasi outlier. Dalam metode ini, dengan meminimumkan median kuadrat sisaannya, penduga yang dihasilkan akan lebih resisten terhadap outlier. Data yang digunakan pada penelitian ini adalah data sekunder tentang produksi jeruk di Indonesia tahun 2016 yang diambil dari Kementrian Pertanian. Ukuran data yang digunakan adalah sebanyak 34 yaitu banyak provinsi di Indonesia. Dengan variabel dependen adalah produksi jeruk, dan variabel bebas (independen) yang diambil sebanyak tiga yaitu luas panen, curah hujan, dan suhu. Proses pertama adalah mendeteksi apakah ada outlier pada data, dan melakukan uji asumsi klasik. Kemudian mencari model regresi dengan metode Least median square (LMS). Apabila dibandingkan, hasil model regresi produksi jeruk dengan metode MLS lebih akurat daripada hasil model regresi dengan metode MKT. Dengan demikian dapat disimpulkan bahwa metode regresi robust Least median square (LMS) cukup layak untuk digunakan sebagai alternatif dalam mencari model regresi pada data produksi jeruk di Indonesia tahun 2016 yang mengandung outlier.
\end{abstract}

Kata Kunci : Least Median Square, metode kuadrat terkecil, outlier.

\section{PENDAHULUAN}

Analisis regresi adalah sebuah analisis statistik yang digunakan untuk menyelidiki dan membangun suatu model matematis untuk menjelaskan bentuk hubungan antara variabel. Analisis regresi yang dilakukan untuk satu variabel independen dan satu variabel dependen disebut analisis regresi sederhana. Jika terdapat beberapa variabel independen maka disebut regresi linear berganda [1]. Salah satu metode yang digunakan untuk mengestimasi parameter regresi adalah Metode Kuadrat Terkecil (MKT). Prinsip MKT adalah meminimumkan jumlah kuadrat sisaan (error). Metode kuadrat terkecil harus memenuhi asumsi-asumsi yang ada sehingga hasil estimasinya memenuhi sifat best linear unbiased estimator (BLUE). Metode kuadrat terkecil mempunyai asumsi-asumsi tertentu yaitu homoskedastisitas, tidak terjadi autokolerasi, tidak terjadi multikolinearitas, dan error berdistibusi normal. Jika tidak memenuhi salah satu asumsi misalnya disebabkan adanya outlier, maka penduga MKT yang diperoleh menjadi tidak efisien [2].

Dalam beberapa kasus dimungkinkan adanya data yang jauh dari pola kumpulan dan keseluruhan, yang lazim didefinisikan sebagai data outlier [3]. Jadi outlier adalah data pengamatan yang sangat berbeda dari data yang lain. Outlier dapat secara serius mengganggu tingkat keabsahan metode kuadrat terkecil [1]. Regresi robust merupakan metode regresi yang digunakan ketika distribusi dari sisaan tidak normal atau ada beberapa outlier yang berpengaruh pada model. Metode ini merupakan alat penting untuk menganalisis data yang dipengaruhi oleh outlier sehingga dihasilkan model yang tahan terhadap outlier [4]. Least median square (LMS) adalah salah satu metode estimasi dalam regresi robust yang digunakan untuk mengatasi outlier. Dalam metode ini, dengan meminimumkan median kuadrat sisaannya, penduga yang dihasilkan akan lebih resisten terhadap outlier [5].

Penelitian ini bertujuan untuk mempelajari dan memahami tentang regresi robust. Selain itu tujuan dari penelitian ini adalah untuk mendeteksi outlier pada data yang digunakan dan menentukan persamaan regresi linear berganda yang mengandung outlier dengan menggunakan metode regresi robust Least median square (LMS). 
Data yang digunakan dalam penelitian ini berupa data sekunder tentang produksi jeruk di Indonesia tahun 2016 yang diambil dari Kementrian Pertanian. Ukuran data yang digunakan adalah sebanyak 34 yaitu banyak provinsi di Indonesia. Variabel bebas (independen) yang diambil sebanyak tiga yaitu luas panen, curah hujan, dan suhu. Langkah yang dilakukan dalam mengestimasi parameter pada regresi robust dengan metode Least Median Square (LMS) adalah melakukan estimasi koefisien regresi pada data dengan metode kuadrat terkecil (MKT). Kemudian menguji asumsi klasik dari model regresi dan mendeteksi adanya outlier pada data.

\section{REGRESI ROBUST}

Regresi robust merupakan metode regresi yang digunakan ketika distribusi dari sisaan tidak normal atau ada beberapa outlier yang berpengaruh pada model. Metode ini merupakan alat penting untuk menganalisis data yang dipengaruhi oleh outlier sehingga dihasilkan model yang tahan terhadap outlier [4]. Ketika menyusun model regresi dan melakukan uji asumsi sering ditemui bahwa asumsi regresi dilanggar, transformasi yang dilakukan tidak akan menghilangkan atau melemahkan pengaruh dari outlier yang akhirnya prediksi menjadi bias. Dalam keadaan ini, regresi robust yang tahan terhadap pengaruh outlier adalah metode yang terbaik. Regresi robust adalah metode yang penting untuk menganalisis data yang terkontaminasi oleh outlier. Regresi robust terdiri dari 5 metode estimasi, antara lain: M-estimator, Least Median Square (LMS)-estimator, Least Trimmed Square (LTS)-estimator, S-estimator, dan MM-estimator [6].

\section{METODE LEAST MEDIAN SQUARE (LMS)}

Least median square (LMS) adalah salah satu metode estimasi dalam regresi robust yang digunakan untuk mengatasi outlier. Pada metode MLS, dengan meminimumkan median kuadrat sisaannya, penduga yang dihasilkan akan lebih resisten terhadap outlier [5]. Metode ini adalah salah satu metode estimasi dalam regresi robust, dimana data outlier yang ada tidak dibuang begitu saja, tetapi diproses dan dieliminasi melalui sebuah iterasi. Jika pada metode kuadrat terkecil hal yang perlu dilakukan adalah meminimumkan jumlah kuadrat sisaan $\left(\sum_{i=1}^{n} e_{i}^{2}\right)$, maka pada LMS hal yang perlu dilakukan adalah mencari nilai median kuadrat sisaan pada setiap iterasi, yaitu:

$$
M_{j}=\operatorname{med} e_{i}^{2}
$$

sehingga terbentuk $M_{1}, M_{2}, \ldots, M_{s}$ yang merupakan median kuadrat sisaan dari setiap $h_{i}$ pengamatan. Untuk mendapatkan nilai $M_{1}$, dicari himpunan bagian data sejumlah $h_{i}$ pengamatan, yaitu:

$$
h_{i}=\left[\frac{n}{2}\right]+\left[\frac{p+1}{2}\right]
$$

dengan $n$ adalah banyaknya data, dan $p$ adalah banyaknya parameter. Dalam perhitungan nilai $h_{i}$ harus selalu dalam bentuk bilangan bulat. Oleh karena itu, jika nilai $h_{i}$ bukan dalam bentuk bilangan bulat maka dilakukan pembulatan ke atas. Demikian seterusnya sampai iterasi berakhir pada iterasi ke$i$ yaitu saat $h_{i}=h_{i+1}$. Setelah itu dicari nilai minimum dari $M_{1}, M_{2}, \ldots, M_{S}$ [7].

Karena LMS merupakan penduga pada regresi robust, maka sama halnya dengan penduga lain pada regresi robust, prinsip dasar dari LMS adalah dengan memberikan bobot $w_{i i}$ pada sehingga data outlier tidak mempengaruhi model parameter taksiran. Bobot $w_{i i}$ dirumuskan dengan ketentuan sebagai berikut:

$$
w_{i i}= \begin{cases}1 & \text { jika }\left|e_{i} / \hat{\sigma}\right| \leq 2,5 \\ 0 & \text { lainnya }\end{cases}
$$

dengan;

$\hat{\sigma}=1,4826\left[1+\frac{5}{(n-p)}\right] \sqrt{M_{j} \min }$

Setelah bobot $w_{i i}$ dihitung, dapat dibentuk matrik $W$ sebagai berikut: 


$$
\boldsymbol{W}=\left[\begin{array}{cccc}
w_{11} & 0 & \ldots & 0 \\
0 & w_{22} & \ldots & 0 \\
\ldots & \ldots & \ddots & \ldots \\
0 & 0 & \ldots & w_{n n}
\end{array}\right]
$$

Setelah terbentuk matriks $W$, maka penaksiran parameter regresi LMS dapat dihitung dengan menggunakan rumus [7]:

$$
\widehat{\boldsymbol{\theta}}_{L M S}=\left(\boldsymbol{X}^{T} \boldsymbol{W} \boldsymbol{X}\right)^{-1}\left(\boldsymbol{X}^{T} \boldsymbol{W} \boldsymbol{Y}\right)
$$

\section{MODEL REGRESI DENGAN METODE LEAST MEDIAN SQUARE (LMS)}

Sebelum melakukan pemodelan dilakukan terlebih dahulu pendeteksian outlier. Pendeteksian outlier dilakukan dengan menggunakan metode DfFITS (Difference fitted value FITS) atau Standardized DfFITS. Suatu data dikatakan terdeteksi outlier apabila nilai $|D f F I T S|>2 \sqrt{\frac{p}{n}}$. Hasil diagnosis metode DfFITS terhadap data dengan $\mathrm{p}$ adalah banyak parameter dana $\mathrm{n}$ adalah banyaknya data diperoleh nilai $\mid$ DfFITS $\mid=2 \sqrt{\frac{p}{n}}=2 \sqrt{\frac{4}{34}}=0,686$. Berdasarkan hasil perhitungan diperoleh bahwa data ke- 2, 15 dan 17 terdeteksi outlier. Sedangkan dengan menggunakan software MINITAB terdeteksi adanya outlier sebanyak 4 pengamatan, yaitu data ke- 2, 12, 15, dan 17.

Selanjutnya dilakukan estimasi koefisien regresi pada data dengan metode kuadrat terkecil (MKT). Didapat model sebagai berikut:

$$
Y_{i}=-309+31,7 X_{1 i}+17 X_{2 i}-45 X_{3 i}
$$

Adapun langkah-langkah pemodelan regresi dengan LMS diawali dengan penentuan $M_{j}$. Untuk menentukan nilai $M_{j}$ yaitu median dari error kuadrat pada iterasi ke- $i$, terlebih dahulu dicari nilai error kuadrat dari MKT dengan jumlah pengamatan pada iterasi ke- $i$.

Diberikan $i=1,2, \ldots, l$ dan berhenti saat $h_{i}=h_{i+1}$, diperoleh iterasi sebagai berikut:

(i) Iterasi ke-1 dengan $n=34$ diperoleh

$M_{1}=$ median $\left\{e_{i}^{2}: i=1,2, \ldots, 34\right\}=8214671,83$, dan

$h_{1}=\left[\frac{n}{2}\right]+\left[\frac{p+1}{2}\right]=\left[\frac{34}{2}\right]+\left[\frac{4+1}{2}\right]=\frac{39}{2}=20$

Artinya pada iterasi ke-2 akan diambil 20 pengamatan yang jarak nilai $e_{i}^{2}$ ke $M_{1}$ nya minimum.

Dengan kata lain dihilangkan sebanyak 14 pengamatan.

(ii) Iterasi ke-2 dengan $n=20$, melalui MKT diperoleh model sebagai berikut:

$Y_{i}=18987+35,2 X_{1 i}-6,75 X_{2 i}-661 X_{3 i}$

dengan demikian diperoleh;

$M_{2}=$ median $\left\{e_{i}^{2}: i=1,2, \ldots, 20\right\}=425581,94$, dan

$h_{2}=\left[\frac{n}{2}\right]+\left[\frac{p+1}{2}\right]=\left[\frac{20}{2}\right]+\left[\frac{4+1}{2}\right]=13$

Artinya pada iterasi ke-3 akan diambil 13 pengamatan yang jarak nilai $e_{i}^{2}$ ke $M_{2}$ nya minimum. Dengan kata lain dihilangkan sebanyak 7 pengamatan.

(iii) Iterasi ke-3 dengan $n=13$, melalui MKT diperoleh model sebagai berikut:

$Y_{i}=15891+35,9 X_{1 i}-3,47 X_{2 i}-562 X_{3 i}$

dengan demikian diperoleh;

$M_{3}=$ median $\left\{e_{i}^{2}: i=1,2, \ldots, 13\right\}=85703,62$, dan

$h_{3}=\left[\frac{n}{2}\right]+\left[\frac{p+1}{2}\right]=\left[\frac{13}{2}\right]+\left[\frac{4+1}{2}\right]=9$ 
Artinya pada iterasi ke-4 akan diambil 9 pengamatan yang jarak nilai $e_{i}^{2}$ ke $M_{1}$ nya minimum. Dengan kata lain dihilangkan sebanyak 4 pengamatan.

(iv) Iterasi ke-4 dengan $n=9$, melalui MKT diperoleh model sebagai berikut:

$Y_{i}=16168+36,4 X_{1 i}-3,78 X_{2 i}-574 X_{3 i}$

dengan demikian diperoleh;

$M_{4}=$ median $\left\{e_{i}^{2}: i=1,2, \ldots, 9\right\}=54019,43$, dan

$h_{4}=\left[\frac{n}{2}\right]+\left[\frac{p+1}{2}\right]=\left[\frac{9}{2}\right]+\left[\frac{4+1}{2}\right]=7$

Artinya pada iterasi ke-5 akan diambil 7 pengamatan yang jarak nilai $e_{i}^{2}$ ke $M_{1}$ nya minimum.

Dengan kata lain dihilangkan sebanyak 2 pengamatan.

(v) Iterasi ke-5 dengan $n=7$, melalui MKT diperoleh model sebagai berikut:

$Y_{i}=10838+34,9 X_{1 i}-2,70 X_{2 i}-385 X_{3 i}$

dengan demikian diperoleh;

$M_{5}=$ median $\left\{e_{i}^{2}: i=1,2, \ldots, 7\right\}=22645,43$, dan

$h_{5}=\left[\frac{n}{2}\right]+\left[\frac{p+1}{2}\right]=\left[\frac{7}{2}\right]+\left[\frac{4+1}{2}\right]=6$

Artinya pada iterasi ke-6 akan diambil 6 pengamatan yang jarak nilai $e_{i}^{2}$ ke $M_{1}$ nya minimum. Dengan kata lain dihilangkan sebanyak 1 pengamatan.

(vi) Iterasi ke-6 dengan $n=6$, melalui MKT diperoleh model sebagai berikut:

$Y_{i}=12263+35 X_{1 i}-2,8 X_{2 i}-436 X_{3 i}$

dengan demikian diperoleh;

$$
\begin{aligned}
& M_{6}=\text { median }\left\{e_{i}^{2}: i=1,2, \ldots, 6\right\}=20680,14, \text { dan } \\
& h_{6}=\left[\frac{n}{2}\right]+\left[\frac{p+1}{2}\right]=\left[\frac{6}{2}\right]+\left[\frac{4+1}{2}\right]=6
\end{aligned}
$$

Iterasi berakhir pada iterasi ke-5, karena $h_{5}=h_{6}$. Dengan berakhirnya proses iterasi sebanyak 5 kali, maka diperoleh 5 buah nilai $M_{j}$ yaitu;

Tabel 1. Nilai $M_{j}$

\begin{tabular}{|l|r|}
\hline Iterasi & \multicolumn{1}{c|}{$M_{j}$} \\
\hline 1 & 8214671,83 \\
\hline 2 & 425581,94 \\
\hline 3 & 85703,62 \\
\hline 4 & 54019,43 \\
\hline 5 & 22645,43 \\
\hline Min & 22645,43 \\
\hline
\end{tabular}

Penentuan parameter regresi LMS didapat berdasarkan hasil perhitungan $M_{j}$ dan $\hat{\sigma}$ yang kemudian dihitung bobot $w_{i i}$. Dengan mensubsitusikan nilai $n=34, \quad p=4$, dan $M_{j}=22645,43$ ke dalam persamaan:

$$
\begin{aligned}
\hat{\sigma}= & 1,4826\left[1+\frac{5}{(n-p)}\right] \sqrt{M_{j} \min } \\
& =1,4826\left[1+\frac{5}{(34-4)}\right] \sqrt{22645,43} \\
& =260,29
\end{aligned}
$$


Selanjutnya dengan menggunakan rumus di bawah ini diperoleh nilai penaksiran parameter

$$
\begin{aligned}
& \widehat{\boldsymbol{\theta}}_{L M S}=\left(\boldsymbol{X}^{\boldsymbol{T}} \boldsymbol{W} \boldsymbol{X}\right)^{-1}\left(\boldsymbol{X}^{\boldsymbol{T}} \boldsymbol{W} \boldsymbol{Y}\right)
\end{aligned}
$$

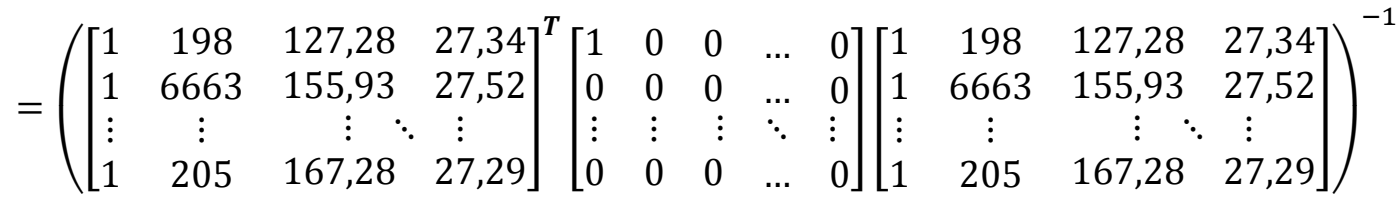

$$
\begin{aligned}
& \left(\left[\begin{array}{ccccc}
1 & 198 & 127,28 & 27,34 \\
1 & 6663 & 155,93 & 27,52 \\
\vdots & \vdots & \vdots & \ddots & \vdots \\
1 & 205 & 167,28 & 27,29
\end{array}\right]^{T}\left[\begin{array}{ccccc}
1 & 0 & 0 & \ldots & 0 \\
0 & 0 & 0 & \ldots & 0 \\
\vdots & \vdots & \vdots & \ddots & \vdots \\
0 & 0 & 0 & \ldots & 0
\end{array}\right]\left[\begin{array}{c}
6896 \\
459149 \\
\vdots \\
18352
\end{array}\right]\right) \\
& =\left(\begin{array}{cccc}
856,341999 & -0,092568 & -0,167197 & -29,950513 \\
-0,092568 & 0,000062 & -0,000036 & 0,00333 \\
-0,167197 & -0,000036 & 0,000202 & 0,005174 \\
-29,950513 & 0,00333 & 0,005174 & 1,050896
\end{array}\right)\left(\begin{array}{c}
18913 \\
2890437 \\
3058068,86 \\
514346,95
\end{array}\right) \\
& =\left(\begin{array}{c}
12176,37512 \\
31,18644 \\
12,469467 \\
-480,128192
\end{array}\right)
\end{aligned}
$$

Dengan demikian model regresi dengan metode regresi robust Least median square (LMS) adalah

$$
\widehat{y}_{\iota}=12176,37512+31,18644 x_{1 i}+12,469467 x_{2 i}-480,128192 x_{3 i}
$$

Dalam penelitian ini digunakan RMSE untuk mengetahui seberapa akurat model yang dibentuk.

Tabel 2. Tabel Perbandingan Keakuratan Model

\begin{tabular}{|c|c|}
\hline Metode & RMSE \\
\hline MKT & 55616,97 \\
\hline LMS & 55679 \\
\hline
\end{tabular}

Berdasarkan Tabel 2, dapat disimpulkan bahwa model yang didapatkan dari metode MKT lebih akurat.

\section{PENUTUP}

Dalam pendeteksian outlier, dengan menggunakan software MINITAB terdeteksi adanya outlier sebanyak 2 pengamatan, yaitu data ke- 2 dan 17. Sedangkan dengan menggunakan metode $D f F I T S$, terdeteksi adanya outlier sebanyak 3 pengamatan, yaitu data ke- 2, 15 dan 17. Model regresi yang diperoleh menurut metode MKT dan LMS berturut-turut:

dan,

$$
\widehat{y}_{\iota}=-309+31,7 x_{1 i}+17 x_{2 i}-45 x_{3 i}
$$

$$
\widehat{y}_{l}=12176,37512+31,18644 x_{1 i}+12,469467 x_{2 i}-480,128192 x_{3 i}
$$

Apabila dibandingkan, hasil model regresi dengan metode MKT lebih akurat daripada hasil model regresi dengan metode LMS. Dengan demikian dapat disimpulkan bahwa metode regresi robust Least median square (LMS) tidak cukup layak untuk digunakan sebagai alternatif dalam mencari model regresi pada data produksi jeruk di Indonesia tahun 2016 yang mengandung outlier. 


\section{DAFTAR PUSTAKA}

[1]. Montgomery DC. and Peck. Introduction to Linear Regression Analysis. New York: John Wiley \& Sons, Inc; 1991.

[2] Gujarati DN dan Porter DC. Dasar-dasar Ekonometrika Buku 1 Edisi Kelima. Jakarta: Salemba Empat; 2010.

[3]. Rousseeuw PJ And Zomeren BC. Unmasking Multivariate Outliers and Leverage Points. Journal of the American Statistical Association. 85: 633-639; 1990.

[4]. Draper NR and Smith H. Analisis Regresi Terapan Edisi kedua. Bambang Sumantri, penerjemah. Jakarta: Gramedia Pustaka Utama. Terjemahan dari: Applied Regression Analysis $2^{\text {nd }}$ edition; 1992.

[5]. Rousseeuw PJ. Least Median of Squares Regression. Journal of the American Statistical Association. 79: 871-880; 1984.

[6]. Chen, C,. Robust Regression and Outlier Detection with the ROBUSTREG Procedure. Paper 26527. North Carolina: SAS Institute; 2002.

[7]. Parmikanti K. Model regresi kandungan batubara menggunakan metode Least Median of Squares. Prosiding Seminar Nasional Sains dan Teknologi Nuklir PTNBR; 2013.

MIMI KURNIATI

YUNDARI

SETYO WIRA RIZKI
: Jurusan Matematika FMIPA UNTAN, Pontianak, mimi.kurniati07@gmail.com

: Jurusan Matematika FMIPA UNTAN, Pontianak, yundari@math.untan.ac.id

: Matematika FMIPA UNTAN, Pontianak, setyo.wirarizki@math.untan.ac.id 
